\title{
Research on the Current Situation and Cultivation of English Learning Motivation of Non - English Majors
}

\author{
Xue Mei \\ Haikou College of Economics, Haikou, Hainan, China, 110372
}

Keywords: Non - English Majors; College Students; English Learning Motivation; Status Quo and Training

\begin{abstract}
English is a language discipline, but also a tool discipline, with the current process of globalization, English as a major communication language, combined with years of teaching experience, the impact of student English learning quality and efficiency of many factors. But the most important factor in the quality of students' English learning is learning motivation, but for now, some non-English majors in our country, many students lack the motivation for English learning, the phenomenon of student grade differentiation in class more serious, this phenomenon seriously affected the whole class English teaching process and quality. Therefore, this article analyzes and probes into the present situation and cultivation of non-English majors' English learning motivation, so as to effectively improve the quality and level of English learning in our college students.
\end{abstract}

\section{Introduction}

For college students, the students are more mature and psychological, many students in the university for the actual study of the goal and so have a clear plan, the students in the university during the study is mainly driven by the students to learn motivation. The so-called learning motivation refers to the internal motivation to directly promote a person to learn, English learning motivation is to enable students to actively and actively participate in English learning activities, which is effective to enhance the importance of college students English level. Therefore, in order to effectively improve the non-English majors' English proficiency, we need to focus on constantly stimulating and cultivating students' motivation for English learning. Only in this way can we achieve the goal of English teaching in colleges and universities, and effectively improve our college students' English language proficiency.

\section{The Status Quo of Non - English Majors' English Learning Motivation}

Certificate Motive. English subjects have become compulsory courses in Chinese university teaching, but at present there are many non-English majors for English learning interest and enthusiasm are not enough, so the class middle school students in English performance there is a big difference [1]. But at present, many non-English majors in our country have the motivation to learn English. First of all, at present our university, students must get the CET certificate to get the diploma, so many non-English majors can of graduation, in order to be able to find a good job after graduation. Many of the students are for their own future better development, so in the invisible also formed a student's English learning motivation. Of course, some of the students are only in order to cope with the examination, for the study of English only to pass the score, for the actual learning process and the way does not care, it is clear that if the student is only a certificate as a student's English learning motivation greatly affect the students' ability to apply English, tend to be prone to high scores of low energy phenomenon.

Social Motivation. With the current process of globalization, English in people's real life and work in the application of ubiquitous, such as foreign work in the exchange of people, e-mail, reading English contracts require students to have a higher level of English [2]. For example, in the social environment, these social phenomena are motivations for non-English majors to learn English, as well as in the case of students watching foreign films, periodicals and access to literature. 
Students and their own society in order to effectively integrate, and only continue to learn how to adapt to the development of society, and now many of our non-English majors are in such a motivation for English learning. It is clear that in the current non-English majors in China, a considerable part of the students are in such external motives, to learn English, students in such a motive can really improve the students' English proficiency and grades. But at the same time under this idea, college English will give a lot of non-English professional students caused great pressure, more difficult to establish students' interest in English, and students for English learning time must not be long.

Interest Motives. Through the observation found that many students in the English learning process, is the interest as a practical English learning motivation, many students themselves has a very strong desire to learn a new language, hoping to learn more knowledge and culture. This part of the non-English majors, the study of English is clearly not to cope with the examination, but also not to the ability to find English as a good job conditions, these students for the English learning is active, positive, enjoy [3]. Therefore, in the actual non-English major teaching, this part of the students usually have a great interest in the study of English knowledge, so in non-English major English teaching, many students because of the actual learning motivation, students for English courses the attitude will have a big difference, the actual level of English and performance will also have a big difference. In short, we should pay attention to cultivating non-English majors' inner motivation for English learning, so that students can truly and persistently learn English, and constantly improve the enthusiasm and initiative of non-English majors in English learning, so as to effectively enhance our college English Teaching level, to enhance the overall quality of our higher talents.

\section{The Cultivation of Non - English Majors' English Learning Motivation}

The Combination of Intrinsic Motivation and External Motivation. Teachers themselves to realize that a fluent in English is a lot of students dream of things, but in the actual learning process, really backfire, teachers to pass to students fluent in English, is not achieved overnight, for English Learning no matter what time is late. Therefore, teachers should pay attention to understand the practical motivation of students in English learning, to ensure that students can effectively combine the intrinsic motivation and external motivation for English learning [4]. In fact, external motives and intrinsic motivation itself can be mutually reinforcing and complement each other, but the most critical focus should be to constantly stimulate students' intrinsic motivation for English learning. At present, Chinese non-English majors learning English process, many students are in external motives, and even some students do not have the motivation to learn English. So this requires teachers in addition to their own to have a higher level of English, but also have a high level of teaching and professional teaching attitude, the student's external motivation effectively into the intrinsic motivation.

Enhance the Professional Level of Teachers. In the process of teaching non-English majors, we should pay attention to constantly improve the professional level of teachers themselves, to ensure that teachers have a solid basic skills of language, so as to effectively avoid the teaching process, the basic grammatical errors [5] The teachers in English teaching, you can use the contrast between English and Chinese teaching methods, so as to effectively avoid non-English majors in English learning by the Chinese interference, teachers in the actual teaching conscious to the students to explain some of the different knowledge of English and Chinese structures can be effective To enhance the language sensitivity of non-English majors, so as to better help students to establish cross-cultural communication awareness. For example, in the study of refusal to invite the statement, the structure of English is: Statement + additional information. I feel worried because then the teacher can effectively combine the Chinese grammatical structure, through this way to effectively improve the cross- Exchange awareness. Teachers to recognize that college English teaching is to knowledge and language as the goal, and constantly improve their own quality, especially for college non-English majors in English teaching, teachers need to practice the actual teaching activities of the system. The teaching of English through this language contrast between 
the effective promotion of classroom teaching effectiveness and fun, to achieve in the comparative study found the problem, to upgrade itself as a good language researcher. Only the teachers themselves have a wealth of knowledge, the students fully understand and understand, while the teaching class has a good ability to control, to fully demonstrate their own charisma, and only then can really be the students love and respect, so that Non-English majors can generate motivations for learning English, so as to better achieve the goal of practical teaching.

Establish Good Relationship between Teachers and Students. To effectively cultivate non-English majors 'English learning motivation, we should pay attention to constantly improve the professional quality of English teachers, in the actual teaching process to establish a good relationship between teachers and students to enhance students' confidence in English teachers [6]. Therefore, in the actual teaching process, teachers need to pay attention to their own words and deeds, good role model, in the actual English teaching process, to be good at discovering the problems in teaching, continuous analysis of the problem, timely solve the problem, always adhere to the student-oriented, determined to use their words and deeds to promote the growth of students. In addition, teachers in the teaching process, we should pay full attention to each student to establish a good relationship, and actively into the hearts of students to understand the psychological thinking of students in the actual teaching to be reward and punishment clearly, today's students generally inner comparison Sensitive and vulnerable, teachers in the actual teaching process, we should pay attention to grasp the sense of proportion, and promote the healthy growth of students. The relationship between teachers and students will greatly affect the attitude of students for a discipline, so teachers need to understand the good relationship between teachers and students is to enhance the efficiency of English classroom teaching an important factor and the key, teachers in the actual teaching process to gradually form the students' English learning motivation.

Rich Teaching Form. In the non-English language teaching process, teachers should pay attention to fully grasp the language knowledge to explain, training and other knowledge of the balance between the relationships. So as to better realize the content and goal of college English teaching. In the teaching of non-English majors, teachers should know that they are faced with a special group. Students have a certain English foundation, but at the same time, not solid and practical ability is not strong [7]. Students in the process of learning English, the students are different goals, or there is no goal, a little student is to learn for interest, a little student is to test and learn, and some students have their own ability to learn, and some need to rely heavily on teachers' words and deeds. Therefore, in such an environment, teachers themselves should pay attention to the continuous enrichment of the actual form of teaching, to ensure that every student can learn in the classroom to obtain new knowledge, so that students can enjoy the English learning to the students themselves bring joy broaden the horizons of students. In the current university teaching process, English ability is the key link in the whole education system, so even for non-English majors, still have the ability to read and write, teachers in the actual teaching process can be effective Interspersed with some Western history and culture, learning skills and research skills and other aspects [8]. In this way, the content of the college English teaching course is effectively enriched, and the language skills are used to serve the students 'learning, life, work and research, and so on, and the students' motivation for English learning is continuously improved.

Continuously Carry out Teaching Innovation. In the course of college English teaching in our country, non-English majors' English learning is usually based on self-study. Many students do not learn from English because of their motivation. They lead to many students studying in college English[9]. Students lack of independence and innovation, for the study of English is also a lack of effective methods, skills and interests, for the study of English is also a lack of lasting adherence, so teachers in the actual teaching process, we should pay attention to continuous teaching innovation, Effective active classroom teaching atmosphere, and constantly improve the non-English majors for English learning interest. It is necessary to pay attention to the extracurricular learning of students in class teaching. For example, after the actual teaching, students can ask the students to inquire about the relevant information give the student a detailed URL. In this way, to promote students to better implement the relevant learning tasks to ensure that students can better put into action, the 
establishment of students self-learning awareness and ideas, and gradually enhance the interest of students in English learning, effective training of non-English majors students' English learning motivation.

\section{Conclusion}

In short, for non-English majors in English teaching, we should pay attention to continuously improve students' motivation for English learning, only to ensure that students have enough motivation to learn English, so as to ensure that students can long-term, independent learning English to achieve English as a skill of their own. Therefore, teachers should pay attention to the initiative of the relevant motivation theory, combined with the actual situation of students for students to explore a more appropriate teaching method to achieve the students from the English learning autonomy to achieve English learning.

\section{References}

[1] Zhang Zhonghui. Non-English majors' English learning motivation empirical study[J]. Journal of Jiyuan Vocational and Technical College, 2010, 01: 95-98

[2] Zhang Zhonghui, Luo Yanzi. An Empirical Study on English Learning Motivation of Normal University Students - Taking Tianshui Normal University as an Example[J]. Journal of Tianshui Normal University, 2010,03: 125-127.

[3] Li Jinyuan. English major college students learning motivation decline [D]. Qufu Normal University, 2016

[4] Wang Ling. Non-English Majors' Motivation Decline on English Autonomous Learning [D]. Changsha University of Science and Technology, 2015

[5] Liu Meina. Non-English majors' English learning motivation research[D]. Northeast Normal University, 2007

[6] Meng Siwen. To stimulate non-English majors in English learning motivation method[D]. Harbin Normal University, 2015

[7] Xu Shujuan. Non-English majors' foreign language learning motivation and learning subjective tendencies[D]. Xihua University, 2012

[8] Qi Haizhen. Non-English majors in English learning motivation to decline[D]. Xi'an University of Engineering, 2016

[9] Chen Lifang. Non-English majors' English learning motivation and relevance of English scores [D]. Jiangxi Normal University, 2009 